\title{
Techno economic simulation model of power grid investment considering demand side resources and transmission and distribution price
}

\author{
Liang Wang ${ }^{1 *}$, Siyuan Yin ${ }^{1}$, Yongjuan Qian ${ }^{1}$ \\ ${ }^{1}$ State Grid Hebei Economic Research Institute, Shijiazhuang, Hebei,050000, China
}

\begin{abstract}
With the deepening of market-oriented reform of power system, the investment planning of power grid is affected by many factors. According to the actual business process of power grid investment planning, on the basis of traditional power grid planning ideas, the introduction of system dynamics analysis tools will establish a feedback relationship model for many factors related to power grid investment planning, such as economy, security, demand side resource (DR), transmission and distribution price, and carry out simulation calculation, which can provide a reference for making reasonable policy recommendations for power grid investment. The results show that grid companies can adjust their investment plans by themselves in order to meet the grid reliability and under the incentive of the government's transmission and distribution price policy. the adjustment of transmission and distribution price has the inherent characteristics of decreasing volatility, which can be more obvious when reducing the reliability requirements.
\end{abstract}

\section{Introduction}

The main task of traditional power grid planning is to determine the optimal system construction scheme according to the results of spatial load forecasting in planning period and the basic conditions of the existing network, so as to minimize the construction and operation costs of the transmission system on the premise of meeting the load growth and safe and reliable power supply. With the deepening of the reform of the power market system and the more important role of demand side resources in the power grid, the power grid planning is facing more complexity. When making investment decisions, the power grid decision-makers should comprehensively consider the power grid reliability, the profit objectives of the power grid enterprises, the local economy and load development and other factors. With the deepening of the reform of the power market system and the more important role of demand side resources in the power grid, the power grid planning is facing more complexity. When making investment decisions, the power grid decision-makers should comprehensively consider the power grid reliability, the profit objectives of the power grid enterprises, the local economy and load development and other factors[1-2]. At present, the relevant research of power grid planning focuses on the security of power grid planning, considering the background of carbon emission reduction, smart grid and so on[3-4]. There is no comprehensive consideration of power grid load demand change, power grid operation security and reliability, power grid operation economy, power system demand side resources, political and social environment factors. Therefore, it is necessary to further study the problems of power grid investment planning under the influence of comprehensive factors, establish a simulation model of power grid investment planning to adapt to the current power system reform environment, and provide tool support for decision makers.

\section{System dynamics and its application in power grid investment}

System dynamics is a discipline of analyzing and researching information feedback system, and it is also an interdisciplinary subject of understanding system problems and solving system problems. It is a science that uses simulation technology as a tool to study complex economic and social problems. The key to build the system dynamics model is to determine the boundary, elements and functions of the system, and then build the connection between the elements related to the system functions. The modeling steps are divided into system structure analysis and system model construction.

At present, there are few temperatures on the research of power grid investment planning by using system dynamics in China. Wang Wei used system dynamics to build a power grid investment planning model in the article of "system dynamics modeling and medium voltage distribution network structure optimization of

*Corresponding author's e-mail: 18003217226@163.com 
power grid investment planning" in 2007, but it did not consider the constraints of demand side resources[5]. Zhou Lisha's viewpoint of system dynamics in power grid project management is discussed in the article of "Research on system dynamics simulation of smart grid project management model"[6]. Han Dong used system dynamics to describe the dynamic evaluation method of smart grid in 2012 "dynamic evaluation method of smart grid based on System Dynamics"[7]. None of the above literature deals with the research topic of this paper.

\section{$3 \quad$ Construction of system dynamics simulation model for power grid investment planning}

\subsection{Causality diagram of grid investment planning}

In the current environment of separation of power plant and grid, the reform of power market is accelerating, and the investment strategy of power grid enterprises is affected by many factors. In this paper, from the perspective of government planning and power regulatory authorities, the dynamic system of power grid investment behavior is described from the macro level, and the boundary conditions and connotation of the system are described by using the theory and analysis tools of system dynamics. In order to facilitate the construction and elaboration of the model, the following assumptions are set:

- The investment behavior of power grid capacity is mainly affected by the reliability of power grid, government regulatory policy and vertical market power of power grid.

- Demand side resources can reduce and delay grid investment.

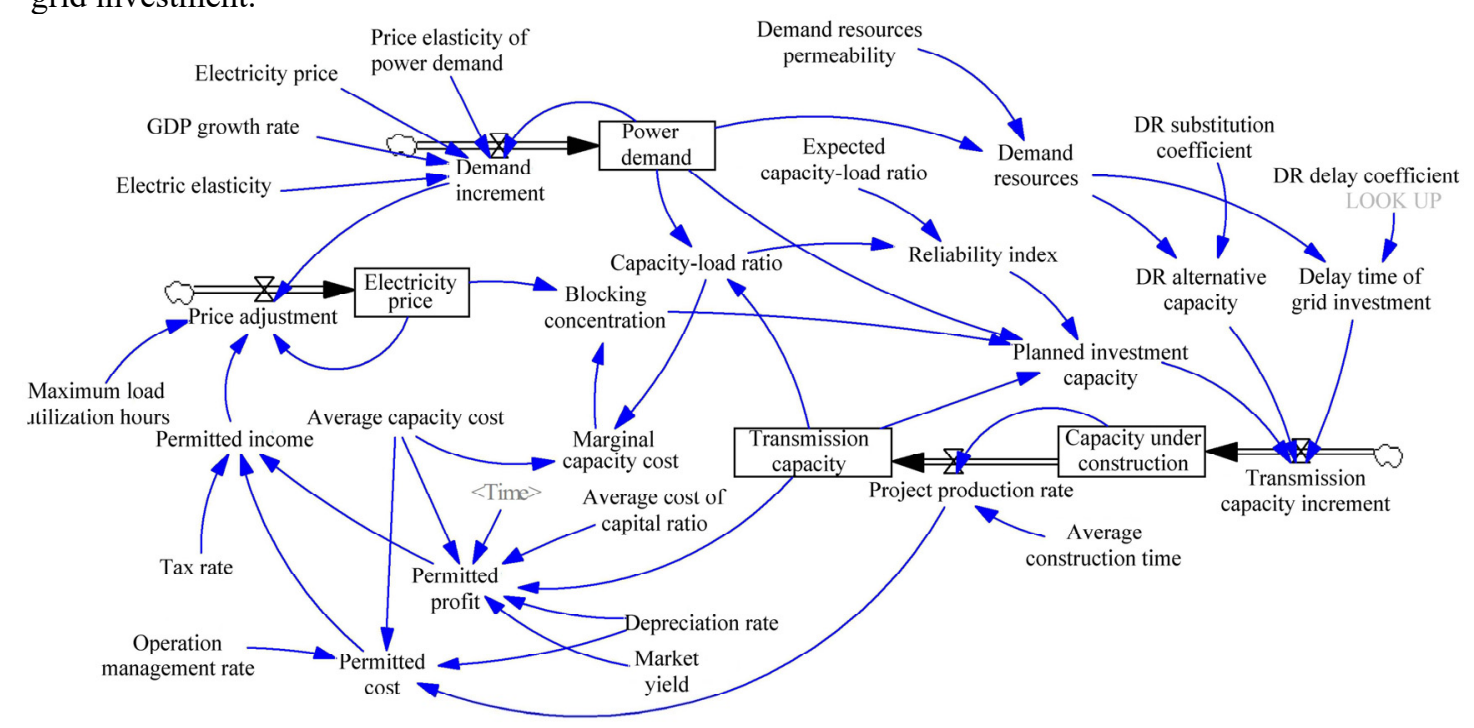

Figure 1. stack flow diagram of power grid investment planning system
- The load demand of power grid is mainly affected by the price elasticity and the state of national economy.

- The model only considers the role of grid vertical market power. For the long-term transmission congestion caused by insufficient network adequacy, transmission companies can use the vertical market power in power transmission to obtain congestion revenue. The government mainly formulates regulatory and regulatory policies for this market power.

- The government's regulation policy chooses the regulation mode of cost plus, which allows the power companies to collect the cost of power supply services (cost fee) and reasonable return on investment (surcharge). The target of regulation is electricity price, which is required

\subsection{Stack flow diagram of grid investment planning system}

According to the causal feedback relationship between various decision factors shown in Figure 1, the system dynamics stack flow diagram model of power grid investment planning is constructed, as shown in fig.1. Considering that the stack flow graph model includes the factors with time-varying such as load demand and electricity price, this chapter will assume that the time category and simulation time of the system dynamics model are 10 years, and in order to ensure that the change of electricity price can have a more significant impact on the adjustment of power supply and demand balance for more than one year, the model needs to ensure a smaller time resolution. Here we assume that The time step of the system dynamics model is 0.25 . to reflect the cost.

3.2.1 Power demand growth cycle. Power demand is affected by two aspects. On the one hand, driven by market awareness, power users adjust their own load 
plans according to the signals of market price, which is expressed in the form of price elasticity coefficient of power demand. on the other hand, affected by the development of macro-economy, the growth of power demand and the growth of GDP show certain correlation characteristics, which is expressed in the form of price elasticity coefficient of power.

$$
D(t)=\operatorname{INTE} G(\Delta D(t))
$$

$$
D(t)=D(t) \times v_{G D P} \times \varepsilon_{1} \times P_{1}^{\wedge \varepsilon_{2}}
$$

In the formula, $D(t)$ is power demand, $\Delta D(t)$ is power demand increment, INTEG () is state equation, indicating an integral relationship, $v_{G D P}$ is GDP growth rate, $\varepsilon_{1} 、 \varepsilon_{2}$ are power elasticity coefficient and power demand price elasticity coefficient respectively, $P_{1}$ is sales price.

3.2.2 Investment planning. The capacity investment of power grid enterprises is mainly considered in two aspects. First of all, according to the existing capacity to meet the load demand, determine the future expansion plan to meet the requirements of power grid capacity adequacy; second, according to the vertical market power in the power market, the government departments formulate corresponding control and incentive policies for the reasonable income of power grid enterprises, which are reflected in the adjustment of transmission and distribution price, and then the power grid enterprises weigh the price and marginal expansion Cost, and then determine their corresponding willingness to invest.

$$
\begin{array}{r}
S_{\text {inc }}(t)=D(t) \times \varphi_{\text {rel }}+S(t) \times \varphi_{\text {obs }} \\
\varphi_{\text {rel }}=\left\{\begin{array}{l}
0,\left(\lambda>\lambda_{\exp }\right) \\
\lambda_{\exp }-\lambda,\left(\lambda<\lambda_{\exp }\right)
\end{array}\right. \\
\varphi_{\text {obs }}=\left\{\begin{array}{l}
0,\left(1-P_{2} / C_{\text {mar.cap }}<0\right) \\
1-P_{2} / C_{\text {mar.cap }},\left(1-P_{2} / C_{\text {mar.cap }}>0\right)
\end{array}\right.
\end{array}
$$

In the formula, $S_{\text {inc }}(t)$ and $S(t)$ are planned investment capacity and grid transmission capacity respectively; $\varphi_{\text {rel }}$ and $\varphi_{o b s}$ are reliability index and congestion concentration index respectively; $\lambda$ and $\lambda_{\text {exp }}$ are capacity load ratio and expected capacity load ratio respectively; $\quad P_{2}$ is transmission and distribution price; $C_{\text {mar,cap }}$ is marginal capacity cost.

3.2.3 Demand side resource substitution. In the current situation of increasing penetration, demand side resources play a role of replacing supply side capacity in the power system. It can delay or replace part of the supply side expansion plan to give full play to the role of demand side resources in the power system.

$$
S_{D R}(t)=D(t) \times \beta
$$

$$
\begin{aligned}
S_{D R}^{r e p}(t) & =S_{D R}(t) \times \beta_{1} \\
T_{D R}^{d e l}(t) & =\operatorname{LOOKUP}\left(S_{D R}\right) \\
\Delta S(t) & =\operatorname{DELAY}\left(S_{\text {inc }}-S_{D R}^{r e p}, T_{D R}^{d e l}\right)
\end{aligned}
$$

In the formula, $S_{D R}(t), S_{D R}^{r e p}(t)$ and $\Delta S(t)$ are demand side resources, demand side resource substitution capacity and new transmission capacity respectively; $\beta$ and $\beta_{1}$ are demand side resource permeability and DR resource substitution coefficient respectively; $T_{D R}^{d e l}$ is demand side resource delay investment time; $\operatorname{LOOKUP()}$ is demand side resource delay coefficient table function; DELAY() is delay function.

3.2.4 Transmission capacity construction. This paper considers the construction period of transmission capacity investment project, and sets the delay function from plan formation to project production.

$$
\begin{gathered}
S_{c o n}(t)=\operatorname{INTEG}\left(V_{c o m}-\Delta S(t)\right) \\
V_{c o m}=\operatorname{DELAY}\left(S_{c o n}(t), T_{c o m}\right) \\
S(t)=\operatorname{INTEG}\left(V_{c o m}\right)
\end{gathered}
$$

In the formula, $S_{c o n}(t)$ and $S(t)$ are the transmission capacity under construction and grid transmission capacity respectively; $V_{c o m}$ is the project production rate; $T_{c o m}$ is the average project construction period.

\subsubsection{Government regulation and incentive.} According to the vertical market power of transmission enterprises in the market, the government formulates regulatory and incentive policies, which are reflected in the adjustment of transmission and distribution price. Adjusting the transmission and distribution price according to the income and cost of new asset projects can make the transmission and distribution price effectively reflect the reasonable income of the power grid, and make the transmission and distribution price play an accurate role in stimulating the power grid investment.

$$
\begin{aligned}
& P_{2}(t)=\operatorname{INTEG}\left(\Delta P_{2}(t)\right) \\
& \Delta P_{2}(t)=R_{p e r}(\Delta D(t) \times h)-P_{2}(t-1) \\
& R_{p e r}(t)=\left(I_{p e r}-C_{p e r}\right) \times(1+\omega) \\
& I_{p e r}=\left(S(T) \times C_{\text {ave }, \text { cap }}\right) \times\left(1-\gamma \times \frac{r \times(r+1)^{t}}{(r+1)^{t}-1}\right) \times(1+\phi) \\
& \left.C_{\text {per }}(t)=V_{\text {com }} \times C_{\text {ave }, \text { cap }} \times(\gamma+\xi)\right)
\end{aligned}
$$

In the formula, $\Delta P_{2}$ is the adjustment of transmission and distribution price; $R_{p e r}$ is the permitted revenue; $h$ is the maximum load utilization hours; $I_{p e r}$ is the permitted 
revenue; $C_{p e r}$ is the permitted cost; $\omega, \gamma, r, \phi$ and $\xi$ are tax rate, depreciation rate, market yield, average capital cost and operation management rate respectively.

\section{$4 \quad$ Example analysis}

\subsection{Basic parameter setting}

The main network of a regional power grid is composed of $220 / 110 \mathrm{kV}$ and $110 \mathrm{kV}$ lines. The planning and calculation of $110 \mathrm{kV}$ power grid are carried out, and the apportionment cost of the superior power grid is not included temporarily. The initial capacity of the bus transformer in the power grid is 200mva, and the maximum power demand in the transmission network is currently predicted to be $150 \mathrm{MW}$. Under the condition of ensuring n-1 safety criterion, the expected capacity to load ratio of the power grid in this region is 1.75 . Some model parameters are shown in tab.1.

Table 1. model parameters.

\begin{tabular}{|c|c|c|c|}
\hline model parameter & value & model parameter & value \\
\hline $\begin{array}{l}\text { Price elasticity coefficient of } \\
\text { power demand }\end{array}$ & -0.3 & Depreciation rate & $4 \%$ \\
\hline Electric elasticity coefficient & 0.34 & Operation management rate & $5 \%$ \\
\hline Average capacity cost & $\begin{array}{c}185 \\
\mathrm{RMB} / \mathrm{kW} \cdot \mathrm{a}\end{array}$ & Average cost of capital ratio & $6 \%$ \\
\hline Average construction period & 1.5 years & Market yield & $7 \%$ \\
\hline Interest rate & $4.9 \%$ & Tax rate & $13 \%$ \\
\hline Maximum load utilization hours & $5500 \mathrm{~h}$ & $\begin{array}{l}\text { Initial value of transmission and } \\
\text { distribution price }\end{array}$ & $\begin{array}{c}156 \\
\mathrm{RMB} / \mathrm{MWh}\end{array}$ \\
\hline Average selling price & $\begin{array}{l}1.2 \mathrm{RMB} / \\
\mathrm{kWh}\end{array}$ & DR substitution factor & 0.05 \\
\hline
\end{tabular}

In the model, in order to quantify the effect of demand side resources on delaying the construction of power grid expansion investment by mathematical method, DR delay coefficient is set by the parameter setting form of table function in Vensim. The delay effect of the demand side resources is reflected in the delay investment time of the planned investment capacity of the grid, and the increase of the permeability of the demand side resources in the grid can significantly enhance the demand side's response ability to the load and load elasticity. Here, it is assumed that the demand side resources and the delay grid construction time are in an exponential linear relationship.

\subsection{Scenario simulation}

Improving the reliability of power grid is the primary goal of power grid planning, so the requirement of power grid reliability is directly related to the investment plan of power grid enterprises and the regulatory strategy of the government, as shown in fig.2. Scenario 2 and

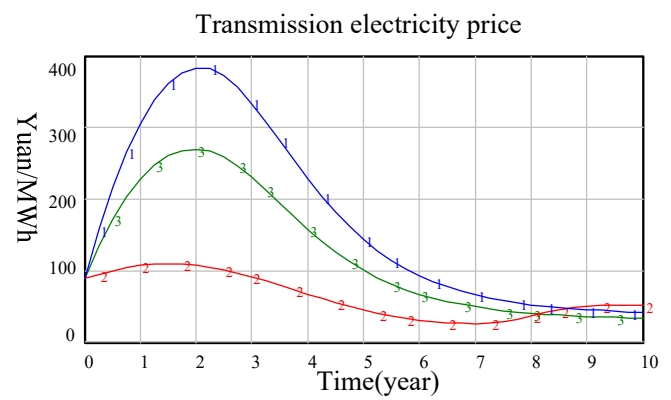

Scenario $1-1-$ Scenario $2-2-$ Scenario $3-3$

Figure 2. sensitivity of investment supervision policies to grid reliability requirements scenario 3 in the figure are the scenarios with expected load capacity ratio of 1.9 and 1.5 respectively. When the reliability requirement of transmission and distribution electricity price is reduced, it can be seen that the transmission and distribution electricity price fluctuates in a decreasing range. Therefore, the low reliability requirement of power grid will reduce the investment interest of power grid enterprises, on the contrary, the government's regulation and incentive policies will change more frequently.

When the demand side resources are introduced into the power grid, the transmission and distribution price increases, as shown in fig.3. And when the penetration of demand side resources is increased in the scenario 2 , it can be seen that the corresponding transmission and distribution price changes from the peak value to the downward trend faster. This shows that demand side resources can delay and replace the construction of power grid investment, and accordingly affect the regulatory incentive policies of the government departments.

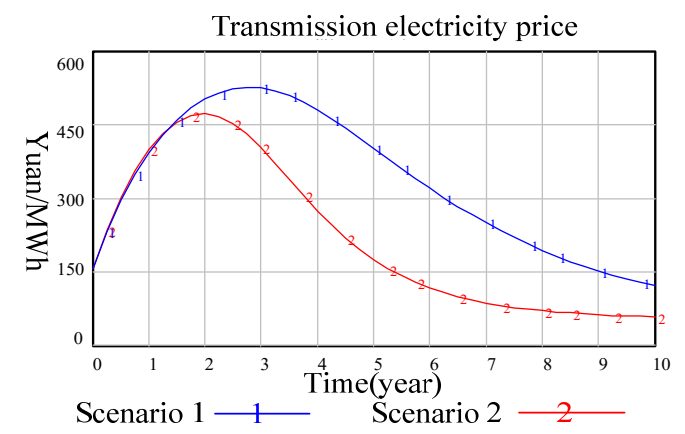

Figure 3. sensitivity of transmission and distribution price to demand side resource permeability. 


\section{Conclusion}

Different from the traditional power grid planning, this paper comprehensively considers the needs of the government regulatory departments and power grid enterprises for power grid planning, and analyzes and discusses the power grid investment plan from a macro perspective. Firstly, with the help of system dynamics, the causal relationship of power grid investment including power grid reliability feedback loop and market supervision incentive feedback loop is established; secondly, based on the causal relationship diagram, the dynamic stack flow diagram of power grid investment planning system is established with the help of Vensim analysis software; finally, in a certain area where the main network is composed of $220 / 110 \mathrm{kV}$ and $110 \mathrm{kV}$ lines, for $110 \mathrm{kV}$ power grid The sensitivity analysis of the impact of grid reliability and demand side resource penetration on grid investment planning and government regulatory incentive policies is carried out. The analysis results show that the model constructed in this paper can effectively realize the system simulation and self-organization simulation of power grid investment; the power grid enterprises can adjust their investment plans under the power grid reliability and the government's transmission and distribution price policy incentives; the transmission and distribution price adjustment has the inherent fluctuation characteristics of decreasing amplitude, which can be more obvious when reducing the reliability requirements. It is shown that the penetration of demand side resources in the grid can replace the capacity expansion of the grid.

\section{Reference}

1. Zábojník J, Dvořák M. (2014) Power grid simulation model for long term operation planning . J. Applied Thermal Engineering, 70(2): 1294-1305.

2. Ashok Bakkiyaraj R, Kumarappan N . (2013)Optimal reliability planning for a composite electric power system based on Monte Carlo simulation using particle swarm optimization. J. International Journal of Electrical Power \& Energy Systems, 47: 109-116.

3. Zhu Y, Li Y P, Huang G H, et al. (2014)Electric power systems planning in association with air pollution control and uncertainty analysis. J. International Journal of Electrical Power \& Energy Systems, 61: 563-575.

4. Kishore T S, Singal S K . (2014)Optimal economic planning of power transmission lines: A review. J. Renewable and Sustainable Energy Reviews, 39: 949-974.

5. Wang W. (2017)System dynamics modeling of power grid investment planning and structure optimization of medium voltage distribution network . North China Electric Power University,Beijing.

6. Zhou L S, Li C, Yu S K.(2012)Research on system dynamics simulation of smart grid project management model. J. East China Electritc Power,40(01):31-34.

7. Han D, Yan Z, Song Y Q, et al. (2012)Dynamic evaluation method of smart grid based on system dynamics. J.Automation of Electric Power System,36(03):16-21. 